Rhode Island College

Digital Commons @ RIC

Master's Theses, Dissertations, Graduate

Master's Theses, Dissertations, Graduate Research and Major Papers Overview

Research and Major Papers

$5-2012$

\title{
School Based Nutrition and Exercise Program
}

Darlene L. Amalfitano

Rhode Island College

Follow this and additional works at: https://digitalcommons.ric.edu/etd

Part of the Public Health and Community Nursing Commons

\section{Recommended Citation}

Amalfitano, Darlene L., "School Based Nutrition and Exercise Program" (2012). Master's Theses, Dissertations, Graduate Research and Major Papers Overview. 164.

https://digitalcommons.ric.edu/etd/164

This Major Paper is brought to you for free and open access by the Master's Theses, Dissertations, Graduate Research and Major Papers at Digital Commons @ RIC. It has been accepted for inclusion in Master's Theses, Dissertations, Graduate Research and Major Papers Overview by an authorized administrator of Digital Commons @ RIC. For more information, please contact digitalcommons@ric.edu. 
Approval Sheet

SCHOOL BASED NUTRITION AND EXERCISE PROGRAM

A Major Paper Presented

by

Darlene L. Amalfitano BSN, CSNT

Approved:

Committee Chairperson

Committee Members

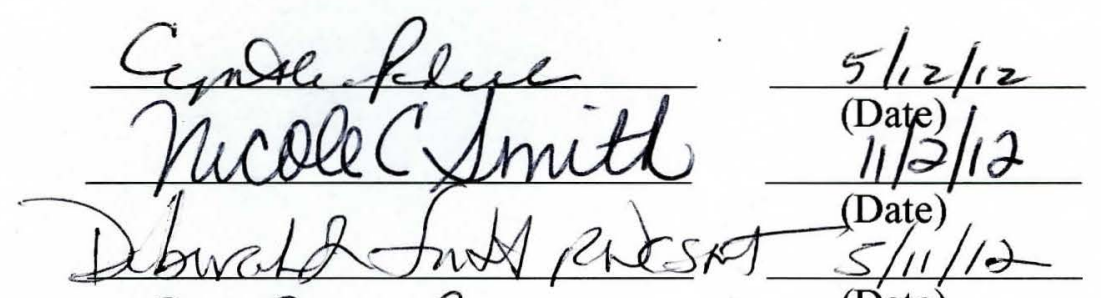

Director of Master's Program

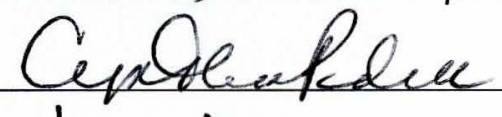

Dean, School of Nursing
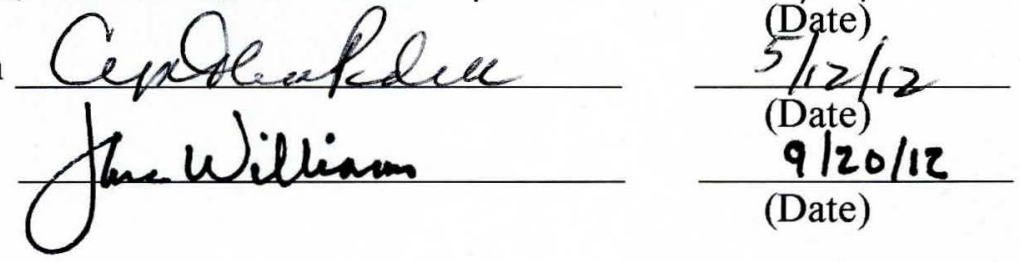
Darlene L. Amalfitano BSN, CSNT

A Major Paper Submitted in Partial Fulfillment

Of the Requirements for the Degree of

Masters of Science in Nursing

in

The School of Nursing

Rhode Island College

2012 


\begin{abstract}
Childhood obesity has more than tripled in the past 30 years and remains high among both boys and girls of all ages and racial and ethnic groups (Koebnick \& Heller, 2010). Childhood obesity is a predictor of obesity during adulthood and is strongly linked to chronic lifestyle diseases (Suarez, Worley, Somers, \& Dones, 2009). The United States, one of the richest countries in the world, spends the most on health care, yet ranks $42^{\text {nd }}$ in life expectancy. Lack of insurance, obesity, and racial disparities are being blamed (America's Health Ranking, 2009). The activity levels and eating behaviors of US children are influenced by many facets of society, including families, community organizations, government, media, and schools. Society needs to take action and participate if the obesity problem is to be solved. Schools play an important role because over $95 \%$ of young people are enrolled in schools. Physical activity and healthy eating have always been part of health education, and research shows a connection between physical activity, good nutrition, and academic performance (Sallis, McKenzie, Kolody, Lewis, Marshall, \& Rosengard, 1999).

The purpose of this project was to develop a school-based nutrition and exercise program aimed at encouraging and teaching healthful lifestyle choices and facilitating behavior change. A premise of the program was that sustainable changes in diet and physical activity accomplished in childhood may be carried into adulthood and may assist in the prevention of obesity in later years. The Ecological Theory by Urie Bronfenbrenner and Nola Pender's Health Promotion Model (2006) were the frameworks that guided this program development. The program duration was six weeks, and
\end{abstract}


sessions met two times per week with $4^{\text {th }}, 5^{\text {th }}$, and $6^{\text {th }}$ grade participants. Children were given a pre-test to assess their knowledge base about healthy food choices, their activity levels, as well as to record a baseline weight. At the conclusion of the program a posttest was given. The majority of the children $(n=15)$ scored the same or higher on the posttest and acknowledged increased knowledge of healthy food choices and increased activity level. Most $(\mathrm{n}=14)$ either remained at the same weight or gained weight, a finding which was expected because the children were in a growth phase and weight loss was not an objective of the program. Overall, the program proved to be successful. The children stated $(n=17)$ that they enjoyed the program, learned some new strategies when choosing a snack, and tasted some new foods that they will continue to eat. Recommendations for further programs would include parent involvement to enhance success. Further research should focus on the effects of programs targeting not just school age but pre-school children 3-5 years of age. There has been expansion of public policy specific to the issue of obesity such as beverage regulation and snack choices available to children, but further change needs to continue in order to have an impact on obesity. The choices offered to our youth today have an impact on obesity both short and long term. 
Table of Contents

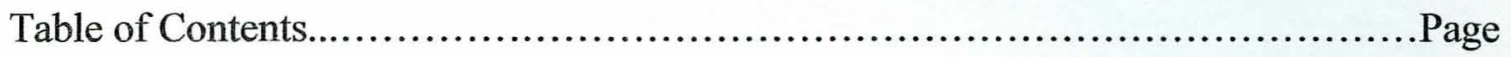

Background/Statement of the problem...............................................

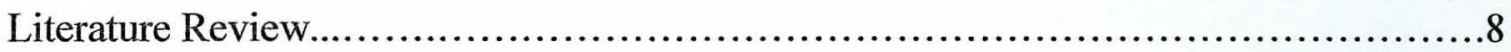

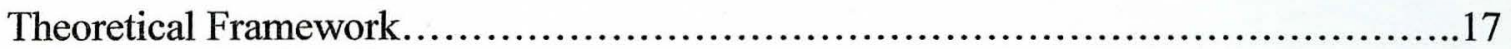

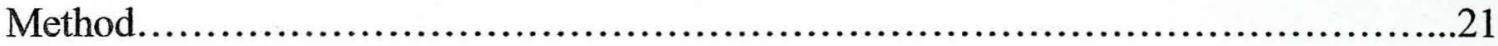

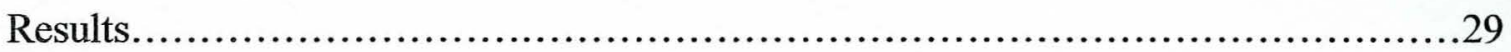

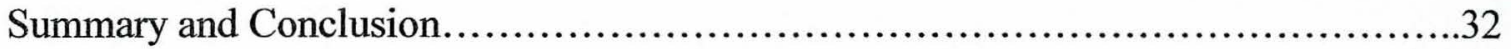

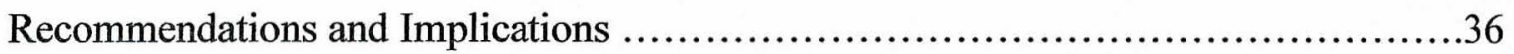

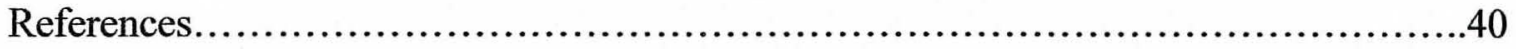

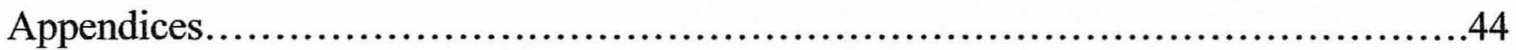




\section{Background/Statement of Problem}

The prevalence of childhood obesity is a great public health concern. Over the past decade, childhood and adolescent overweight and obesity have been recognized in the United States (US) as a rapidly increasing, major pediatric health concern (Lee, Lai, Chou, Chang, \& Chang, 2009). Today in the US, the collective weight problem is linked to 300,000 deaths each year from illnesses such as diabetes and heart disease, and accounts for about $6 \%$ of direct health-related expenditure (Vital Sign, 2010). Overweight and obese youth suffer from co-morbidities such as type 2 diabetes mellitus, non-alcoholic fatty liver disease, metabolic syndrome, and cardiovascular disease, conditions once limited to adults. Type 2 diabetes, although rare among young people 10 years ago, in some communities now accounts for $50 \%$ of new cases among children and adolescents. Childhood obesity is a predictor of obesity during adulthood, which is strongly linked to chronic lifestyle disease (Suarez, Worley, Somers, \& Dones, 2009). Overweight means a body mass index (BMI) at the $85^{\text {th }}$ percentile and below the $95^{\text {th }}$ percentile on growth charts; obesity refers to children and youth between the ages of 2 and 18 who have a BMI equal to or greater than the $95^{\text {th }}$ percentile on the age and gender specific BMI charts (Klish, 2010). A new study found that nearly one third of children nationwide are overweight (32\%) or obese $(16 \%)$, with rates of childhood obesity much higher in the southern states than in other regions (Singh \& Katz, 2010). At present, approximately nine million children over six years of age are considered obese (Klish, 2010). In addition to the physical issues associated with overweight and obesity, psychological issues can also occur. As mentioned in Health Problems of Obese 
Children, teasing about appearance can affect a child's confidence and self-esteem and can potentially lead to isolation and depression. Low self-esteem can affect aspects of health and behavior including activity engagement. Children who are obese often feel they are not competent in physical activity (Lee et al., 2009). Childhood obesity cannot be linked to one cause and is most likely the result of nutritional, psychological, familial, physiological, and environmental factors and policies that influence eating and physical activity (Story, Kaphingst, O’Brien, \& Glanz, 2007). One theme is energy balance, a disproportion between energy intake and energy expenditure (Anderson \& Butcher, 2006). In other words, our young people are making unhealthy choices and are not getting enough physical activity. Children who eat more empty calories and expend fewer calories through lack of physical activity are more likely to be overweight or obese than other children (Lytle, 2009). Anderson and Butcher (2006) indicated the increase in childhood obesity over time indicates an upset in the energy balance. Changes in the food market may be affecting the balance, most notably the increased use of fast food restaurants and especially the role of soft drinks and energy drinks. This may be related to consumer demand, stemming from the increase in households with no full-time homemaker (Lytle, 2009). Reduced access and affordability to fruits and other nutritious foods may also be a contributing factor (Lytle,).

Environment is also a contributing factor to obesity (Anderson \& Butcher, 2006). The congested environment and concern with safety may contribute to fewer children walking to school. Deciding whether to play soccer or basketball outside with a friend or sit inside and watch TV and play video games maybe a difficult choice for many 
children, contributing to decreased activity. A meta-analysis was performed by Smith and Wolf (2008) to examine media exposure and the connection to seven different health outcomes, including obesity. Of the 73 studies, $86 \%$ revealed a strong relationship between screen time (TV, video games, the internet) and obesity. This analysis supports the reality that inactivity is a contributing risk factor to obesity. Clearly, childhood obesity is a complex, growing problem. Many factors contribute to it and have an adverse effect on our youth. It is much easier to prevent obesity than it is to treat it.

The purpose of this project was to develop a program designed to teach healthy lifestyle choices to enhance health. 


\section{Literature Review}

A literature search was undertaken for studies and meta-analyses on school-based interventions that addressed childhood obesity. CINAHL, Pub-Med and Centers for disease Control data bases were searched, using the following key words: childhood obesity; school programs; meta-analysis; interventions; adolescence; exercise; nutrition; and behavior. Some of these terms are very broad, and alone generated an enormous amount of information, so in some instances the key terms were combined to narrow the search.

\section{Obesity in the US}

Obesity is a growing healthcare epidemic in the US that was recognized over a decade ago. At that time, the US Surgeon General issued a call to action to prevent and decrease overweight and obesity in 2001, and again issued a call in 2007 . The objective was to reduce the prevalence of obesity among adults to $15 \%$ by 2010. As of August 2010, no state had met the Healthy People 2010 objective as stated above (CDC, 2010).

More than 72 million US adults are obese, contributing to higher medical costs of $\$ 1429.00$ more per person more than normal weight adults (White House Task Force on Childhood Obesity, Report to the President [White House Task Force], 2010). In 2009, about 2.4 million more adults were obese than in 2007 (CDC, 2010). In nine states, including Okalahoma, Missouri, Arkansas, Mississippi, Alabama, West Virginia, Kentucky, Tennessee, and Louisiana, over $30 \%$ of adults were obese. The remainder of the US, with two exceptions, Colorado and Washington DC, had an obesity rate of between 20\%-29.9\% (CDC, 2010). These alarming statistics are even more frightening 
when considering that in 2000 , no states had obesity rates greater than $30 \%$ (White House Task Force, 2010).

Obesity among adults varies by age and ethnicity, with the greatest prevalence found in adults between the ages of 50-70 years. Non-Hispanic blacks have an obesity rate of $36.8 \%$ overall; non-Hispanics and Hispanics had rates of $30.7 \%$, with residents of the Midwest at $28.2 \%$ and the South at $28.4 \%$. College graduates, both men and women, had lower obesity rates, while higher rates were seen among people who didn't graduate from high school (CDC, 2010).

\section{Obesity in children in the US}

In the US, dramatic increases have been seen in obesity among school-aged children (ages 6-11) and adolescents (ages 12-19) (Seo \& Sa, 2010). During the time period from 1976-1980, the prevalence of obesity was $6.5 \%$ for children and $5.0 \%$ for adolescents (CDC, 2009). By 2007-2008, the rates had tripled to $19.6 \%$ for children and $18.1 \%$ for adolescents. Currently in the US, it is estimated that one third of our children and adolescents are overweight or obese. The epidemic that we are seeing affects boys and girls of all ages, races, and ethnic backgrounds throughout the US (Anderson \& Butcher, 2006).

Obesity rates are higher among minority and low income children as a whole (Seo \& Sa, 2010). Although obesity increased for all children, it increased more for children in low income families and increased most for African American children (Anderson \& Butcher, 2006). Hispanic and American Indian adolescents are also among the populations with increases in obesity in both sexes (Seo \& Sa, 2010). Among boys, 
Hispanics were more likely to have a higher BMI than whites. BMI is a ratio of a person's weight to the square of height multiplied by the conversion factor of 703 ("Overweight and Obesity", 2010). The highest prevalence in girls is observed in African Americans, with $14.5 \%$ of white adolescent girls being obese, compared to $28 \%$ for African Americans and 20\% for Hispanics (IOM website, 2006). A literature review completed by Klish (2010) examined 93 studies that looked at the etiology and pathogenesis of obesity. A small percentage of children (less than $1 \%$ ) become over weight due to an underlying medical problem. Klish noted that more likely than not, children tended to be obese if their parents were obese. It is not known, however, if this is related to genetic factors or if it is because families share the same habits, or a combination of both (Klish). Genetic characteristics of human populations have not changed in the last two decades, while the prevalence of obesity has approximately doubled (Kitzmann, Stanley, Dalton \& Beech, 2010). It is not clear what health behaviors are contributing to the increase in childhood and adolescent obesity; sedentary lifestyle, limited health education, poor dietary habits, genetics, breakdown in family, and socioeconomics are possible reasons (Lytle, 2009). It is fair to say that combinations of all of these factors are responsible.

Schools are a common link between all of these children. Noting that children spend at least six hours per day/five days per week in school, beginning at age five, it would make sense that school-based programs could influence a student's practice on overall health (CDC, 2011). Most schools in the US serve at least one if not two meals per day, five days per week. Schools have the opportunity to influence the nutrition of children on 
a regular basis and to help establish life long eating habits. Schools can also help educate our children on the importance of regular exercise. Zenzen \& Kridli (2008) acknowledged that schools are a significant part of the social environment that shapes children's eating and physical activity habits. Haskins, Paxson, and Donahue (2006) also noted that eating and exercise habits established during childhood will shape eating and exercise in adulthood.

Kitzmann et al. (2010) conducted a meta-analysis, beginning with 98 studies conducted between the years of 1965-2004. The purpose of the meta-analysis was to evaluate lifestyle interventions in the management of children and adolescents who were overweight. Of the 98 studies, 40 studies included a treatment-control comparison and 36 studies included an alternate treatment comparison with parent involvement, for a total of 76 studies. Half of the studies focused on 6-12 year olds, and no studies focused exclusively on pre-schoolers (aged 5 and under). Four studies focused exclusively on children13 years and older and all studies included samples that crossed two or more age categories. Not all of the studies provided information about treatment settings; those specified included schools, pediatricians' offices, obesity clinics, research centers, and one was conducted in a physical training center. The conclusions suggested that some lifestyle interventions can be effective under many conditions, including a combination of diet, activity, and change in weight related health behaviors. Kitzmann et al. (2010) noted that research that used an intervention as simple as using a food diary and eating habit checklist demonstrated significantly better eating habits in participants $(\mathrm{p} .<.05)$ at the end of the treatment. The researchers also noted that parental involvement in lifestyle 
interventions was more successful in terms of achieving weight loss than was non parental involvement. Parental involvement was rated as none (np), low if the youth had primary responsibility, medium if the parents were involved in many aspects (mp), and high if parents were involved in all aspects of treatment (hp). Programs with high parental involvement had outcomes of about $3 / 4$ standard deviation better than medium parental involvement and about $1 / 4$ standard deviation better than low parental involvement; this translated into about a 21 pounds (lbs.) difference between low parental involvement and high parental involvement $(n p=7$ lbs.; $m p=14$ lbs.; $h p=21$ lbs., $\mathrm{p}<.03$ ). Success was noted in children and adolescents, regardless of the duration of the interventions, once baseline habits of healthy eating and exercise had been established. It was difficult to establish what treatment length was most effective because past studies averaged the effective treatment lengths. In the studies examined in the meta-analysis, the length of treatment varied from one month to 24 months. Significant effects $(p<.01)$ were seen in programs lasting less than four months as well as in programs lasting up to eight months. Participants in programs lasting less than four months weighed on average nine lbs. less $(p<.03)$ than participants in a program lasting eight months or longer; however, on average, participants in a shorter program (four months) demonstrated sustained weight loss of seven pounds for seven months post intervention, a value that showed a trend toward significance $(p<.060)$. These results show that treatment length as brief as four months can produce significant change; however it was thought for weight loss to be most beneficial, especially in younger 
children and those who are heavier, longer treatment would accomplish more beneficial results than shorter length treatments.

\section{School based interventions}

Zenzen \& Kridli (2008) conducted an integrated review of school-based obesity prevention programs. The purpose was to provide an overview of the degree of variability in the approaches and theoretical frameworks of school-based obesity prevention programs that utilized more than one intervention. Interventions included dietary habits, physical activity, healthy lifestyle education, and/or parental involvement. A total of 16 studies were included based on the inclusion criteria; 14 studies focused on dietary habit intervention and 14 studies implemented physical activity programs. All 16 studies used healthy lifestyle education; nine of the studies employed parental involvement as a key element in obesity prevention, and nine studies used all four interventions. The authors found that the most effective intervention programs should be guided by behavioral changes. The programs that included all four interventions of dietary habit modification, physical activity modification along with lifestyle education, and parental involvement seemed to be the most effective, however, no specific intervention or combination of interventions proved to generate the most beneficial results. Fourteen of the 16 studies included the interventions of nutrition and physical activity. Programs that involved either physical activity or nutrition teaching alone were not as effective, with only one study based solely in physical activity and one in nutrition teaching. Duration and the impact on BMI seemed to have the most notable limitation. The average length of intervention was 10.4 months; for studies that used BMI as an 
outcome, the average duration was 13 months with a range from three months to 36 months. None of these studies achieved an outcome of significantly lower BMI.

A meta-analysis was performed by Suarez et al. (2009) to examine school-based interventions targeted on childhood obesity. Randomized Controlled Trials (RCT's) from 1995-2007 that used a combination of exercise and dietary behaviors in the interventions were selected. Forty-one papers were identified in the search based on title. Of the 41 papers identified, 22 were excluded because they did not meet the inclusion criteria, and the remaining 19 were included. Duration of the interventions had a positive association with regard to effectiveness ( $d=\geq 12$ month). Programs lasting 1-2 years or greater than two years showed a lower likelihood of participants being overweight or obese with OR's of $0.81(95 \% \mathrm{CI}=0.68,0.92)$ and $0.59(95 \% \mathrm{CI}=0.37,0.94)$ compared with shorter period programs of less than six months. This means the longer the intervention period, the greater the likelihood of weight control. Single interventions were used in five of the studies, while the remaining studies used a combination of interventions including but not limited to parental involvement, physical activity, nutrition education, and a focus on self-image. The $\mathrm{OR}=0.74,95 \%$ with a $\mathrm{CI}=0.60,92$, indicating that the more interventions that were in place, the more effective in decreasing the number of participants who become overweight or obese. The conclusion of the meta-analysis was that school-based programs that used combined interventions of physical activity and classroom curriculum were effective in preventing childhood overweight and obesity. 
Seo \& Sa (2010) conducted a meta-analysis of studies from 1980-2007 to examine effectiveness of obesity interventions among minority children. Minority children included American Indians, Alaska Native, Asian American, Black, African American, Hispanic, Latino, Native Hawaiian, or other Pacific Islanders. Initially the search yielded 1,544 papers; based on inclusion criteria, 40 studies were selected for analysis. Of the 40, 16 were clinic-based, 12 were based in schools, seven in the community, and five were family-based. In terms of research design, 31 were RCT, one non-randomized control trial, seven one-group pre-post trials, and one quasi-experimental design. A total of six studies used only one intervention, 20 studies included two interventions, 13 studies used three component interventions, and one study used a four component intervention. Physical activity, nutrition education, sedentary behavior reduction, and counseling were the interventions used either alone or in combination. Interestingly enough, no evidence was found to support duration of the interventions to have any effect on weight loss. However, the number of interventions had an influence: one component interventions $(\mathrm{n}=6 ; \mathrm{d}=.07)$, indicating a limited effect on reducing outcome measures two-component interventions $(n=20 ; d=.08)$, producing almost the same effect as the onecomponent intervention; three-component interventions $(\mathrm{n}=13 ; \mathrm{d}=.33)$; and fourcomponent interventions $(n=1 ; d=.71)$, indicating the largest effect on weight loss. In terms of intervention settings, clinic-based settings yielded a higher effect size $(d=.35)$ than school-based settings $(\mathrm{d}=.08)$. It should be noted that the majority of school-based settings used only one or two components whereas the clinic-based settings used three or more. Moreover, the entire clinic based settings recruited overweight or obese children, 
which is conducive to yielding higher effect sizes due to statistical regression effect. These findings indicate the importance of addressing multiple components affecting obesity.

It is evident from the studies reviewed that school-based obesity prevention programs can and do have a positive impact on knowledge, attitudes, and behavior in children and adolescents. Schools are an important part of the social environment that shapes a child's dietary and physical activity patterns.

Next, the theoretical frameworks that influenced the program development will be reviewed. 


\section{Theoretical Framework}

The Ecological Theory by Urie Bronfenbrenner (1979) and Nola Pender's Health Promotion Model (Pender et al., 2006) were the frameworks that guided the program development. Ecological Theory emphasizes that a child's biology is a primary environment that fuels development. Interpersonal, intrapersonal, and community factors have an influence on well-being. The interaction between factors in a child's biology, immediate family, community environment, and societal surroundings encourages or detracts from and guides development. Any changes or variance in any one of these areas will affect other areas. Therefore, when looking at a child's development and the immediate environment, the relationship of the larger environment must also be considered (Stokols, 1996). Bronfenbrenner, co-founder of Head Start, used his model to provide a clear view of the problems developing in our society to our children at all levels, including the schools (Addison, 1992). Bronfenbrenner's theory is based on ecology, a branch of biology concerned with the relationship of organisms and their environment. This framework concentrates on subsystems, or components, and the ways these subsystems interact with and influence each other. The subsystems range from immediate processes of development, micro systems, such as family and schools, to patterns of culture or macro systems such as the economy and customs (Gauvain \& Cole, 2005). The Ecological Theory provided a new way of thinking about the many environmental influences that affect human development and illustrates the potential effects that environment can have on development (Gauvain \& Cole). 
The Ecological Theory is defined by two properties, the first being early in life and to a great extent throughout life. The first proposition states that human development takes place over time through processes of more progressively complex interactions between the human person and objects and symbols in the immediate environment. This interaction needs to take place on a regular basis over time. These interactions are found in parent-child and child-child activities, group play, learning new skills and athletic activities (Gauvain \& Cole, 2005). The second proposition states that the form, power, content, and direction of these processes affecting development vary by person. The second property also states that the direction of the first property influences the processes affecting development (Gauvain \& Cole). The environment, both immediate and remote, influences the developing person. Both proposition one and proposition two are interdependent on each other. Schools and teachers can provide stability and long term relationships, but the primary relationship needs to be with someone who can provide a caring safe environment that is meant to last a lifetime (Gauvain \& Cole). Bronfenbrenner's Ecological Systems Theory focuses on the quality and context of the child's environment. Schools and teachers should work to support and create an environment that welcomes and nurtures families as a secondary role, yet the primary support role needs to come from home (Gauvain \& Cole). Children spend on average six and a half hours five days per week at school; schools can make a difference, but sustainable change is a group effort that needs to be nurtured over time to fully reach its potential. 
Pender's Health Promotion Model (HPM) aims to identify predictors of health promoting behaviors (Pender, Murdaugh, \& Parsons, 2006). An assumption of the HPM is that health professionals are a part of the interpersonal environment, which exerts influence on a person throughout their life span. Health promoting behaviors should result in improved health, enhanced functional ability, and better quality of life at all stages of development (Polit \& Beck, 2008).

The HPM is an approach-oriented model, directed at increasing a person's level of well-being. The model uses a multi-dimensional approach to examine how people interact with their environment to pursue health and focuses on three areas: individual characteristics and experiences; behavior-specific cognitions and affect; and behavioral outcomes. The HPM acknowledges that each person has unique personal characteristics and experiences that affect subsequent actions (Peterson \& Bredow, 2009). Variables for behavior specific knowledge and affect have important motivational significance and can be modified through actions. Health promoting behavior is the desired behavioral outcome and is the end point of the HPM (Peterson \& Bredow). A central idea in the HPM is self-efficacy, which is developed through experiences, learning, verbal interaction, and responses to situations. Self-efficacy is the judgment of personal capability to organize and carry out a particular course of action (Pender et al., 2006). Skill in a particular area is not a concern but judgment of one's ability to accomplish a skill that has been learned. This helps to motivate individuals to engage in those behaviors. Feeling efficacy is likely to encourage one to engage in a behavior more frequently and is an important determinant of health promoting behavior. An active role 
by the participant is essential in shaping and maintaining health behaviors. Children, youth, and young adults often, for many reasons, perceive themselves as invulnerable to illness. The HPM does not rely on fear or threat as a primary source of health motivation; therefore it is a model with applicability across the life span (Pender et al.).

The combination of both of these models influenced the design of this program in that the Ecological Theory is a framework for understanding the interrelationship among personal and environmental factors in health and offers a conceptual tool for organizing health promotion interventions. The Ecological Theory goes beyond environmental change strategies by offering a framework for understanding the interplay between persons and the physical environment. This theory helped to focus the interventions to enhance the physical surroundings. The HPM places emphasis on the role of the person as an agent in shaping health practices to optimize individual wellbeing. Health promotion focuses on the modification of health related behaviors; examples of these behaviors are dietary and exercise regimens. Behavior change interventions to encourage health can focus on modifying a single pattern of unhealthy behavior or on the replacement of unhealthy lifestyle with healthier ones. 


\section{Methodology}

\section{Purpose}

The purpose of the program was to develop a school-based nutrition and exercise program aimed at encouraging and teaching healthful life style choices and facilitating behavior change. The desired outcomes were improving knowledge of healthful diet and exercise choices and reducing weight.

\section{Design}

The program was developed, implemented, and tested using a pre-intervention-postintervention design. The intervention was a nutrition and physical activity school based program developed by this writer; the outcome variables measured pre and post intervention included knowledge of healthy diet, exercise knowledge levels, and body weight.

\section{Participants and Location}

The target population included $4^{\text {th }}, 5^{\text {th }}$, and $6^{\text {th }}$ grade students at George J. Peters Elementary School in Cranston, RI. All students were eligible to participate in the program; a sample of 20 children who were interested in participating was desired. All children were invited to participate in the program, including special needs students, for whom accommodations were made as needed. In the event fewer than 20 children responded, flyers and consent forms were to be sent out again. The lowest participation possible would be 15 children. Behavior change is difficult, especially sustaining it, so limits needed to be placed on class size in order to facilitate learning. 


\section{Program Development}

Background and Assessment of Need. Over years of work as a school nurse, the writer had noticed the activity level of the school children decreasing and weight increasing. When talking with children, it was evident that most of the children went home and either watched TV, played video games, or played on the computer; very few went out to play after school. They also stated that while they "sit" they eat chips, ice cream, candy bars versus healthy eating, such as a piece of fruit, yogurt or vegetables. When discussing the weight problem of our youth with other teachers, school nurses and administrators also noted an increase in weight of the children, further stating that they felt the increase was due to poor dietary choices and more sedentary activity.

Development of Program Content. The Literature reviewed on obesity all stressed the importance of a combination of diet, exercise, and behavior change as a way to combat the obesity problem. The author has attended seminars over the years discussing the problem of obesity, the most recent being the "We Can" seminar and the Annual Nutrition Symposium. The basic message conveyed throughout was the need for nutrition education and physical activity education along with behavior change in order to effectively address the issue. Pender's HPM and Urie Bronfenbrenner's Ecological System Theory supported the idea of the importance early interventions in a child's environment to shape behavior later in life. The program was based on these factors and the review of the literature.

The program outline and objectives are identified in Table 1. 
Table 1.

Program Topical Outline and Objectives by Session

\begin{tabular}{|c|c|c|}
\hline Session & Topic & Objective \\
\hline$\underline{1}$ & $\begin{array}{l}\text { Children assent to participate, questionnaire, } \\
\text { weight }\end{array}$ & Baseline Data \\
\hline$\underline{2}$ & Snack vs. Treat-sampling & $\begin{array}{l}\text { Identify the difference } \\
\text { between, benefits vs. risk }\end{array}$ \\
\hline$\underline{\mathbf{3}}$ & $\begin{array}{l}\text { What exercise means to you, preparation for } \\
\text { exercise, and how long to exercise }\end{array}$ & $\begin{array}{l}\text { Identify the importance of } \\
\text { exercise and injury prevention }\end{array}$ \\
\hline$\underline{4}$ & $\begin{array}{l}\text { What to drink-sampling } \\
\text { Time to play by yourself (active participation) }\end{array}$ & $\begin{array}{l}\text { Identify caloric difference in } \\
\text { drinks and exercise done when } \\
\text { alone }\end{array}$ \\
\hline$\underline{\mathbf{5}}$ & Food Pyramid review-identify food groups & $\begin{array}{l}\text { Identify food groups and } \\
\text { important nutrition messages } \\
\text { related to each group }\end{array}$ \\
\hline$\underline{6}$ & $\begin{array}{l}\text { Food Pyramid-Fruit ( } 5 \text { servings) sampling } \\
\text { Time to play by yourself (active participation) }\end{array}$ & $\begin{array}{l}\text { Identify required number of } \\
\text { servings per day, exercise can } \\
\text { be done by yourself }\end{array}$ \\
\hline$\underline{7}$ & $\begin{array}{l}\text { Food Pyramid-grains ( } 3 \text { servings) sampling } \\
\text { Time to play by yourself (active participation) }\end{array}$ & $\begin{array}{l}\text { Identify required number of } \\
\text { servings per day, exercise } \\
\text { done by yourself }\end{array}$ \\
\hline$\underline{8}$ & $\begin{array}{l}\text { Food Pyramid-vegetables (2-3) cups-sampling } \\
\text { Time to play two of you (active participation) }\end{array}$ & $\begin{array}{l}\text { Identify required servings per } \\
\text { day required, exercise done } \\
\text { with two }\end{array}$ \\
\hline 9 & $\begin{array}{l}\text { Food Pyramid-meat and beans-(5-6 oz dly)- } \\
\text { sampling } \\
\text { Time to play two of you (active participation) }\end{array}$ & $\begin{array}{l}\text { Identify required servings per } \\
\text { day-choices available, exercise } \\
\text { done with two }\end{array}$ \\
\hline$\underline{10}$ & $\begin{array}{l}\text { Food pyramid-oils (5-6 tsp) and milk ( } 3 \text { cups)- } \\
\text { sampling } \\
\text { Time to play with a crowd (active participation) }\end{array}$ & $\begin{array}{l}\text { Identify required servings, } \\
\text { available forms and choices, } \\
\text { exercise done with a crowd }\end{array}$ \\
\hline$\underline{11}$ & $\begin{array}{l}\text { Time of day to eat-sampling } \\
\text { Time to play with a crowd (active participation) }\end{array}$ & $\begin{array}{l}\text { Identify the ideal time of the } \\
\text { day to have meal, exercise } \\
\text { down with a crowd }\end{array}$ \\
\hline$\underline{12}$ & $\begin{array}{l}\text { Summary of program, post test, weight and gift } \\
\text { for completing program }\end{array}$ & Improved knowledge \\
\hline
\end{tabular}




\section{Time Frame and Site}

The developed program was presented at the George J. Peters Elementary School, beginning April 26, 2011, and extended over a six week time period, ending June 2, 2011.

\section{Recruitment}

Permission was granted by the Principal of the school to conduct the program and to use the facility (Appendix A). The RIC IRB approved the program development. An IRB approved consent form (Appendix B) was sent home to parents of all eligible children. The consent form provided the program purpose, a full explanation of the program with all the specifics necessary for parents to explain to their child, and a place for the parent to sign to indicate their consent. There were a total of 128 potentially eligible students. The parent was instructed to place the consent slip in the envelope provided, which include the words "attention nurse." The children returned the envelope to school to their teacher, who then sent the completed forms to the office, and office staff subsequently forwarded them to the nurse. Those children that returned the consent slip first were scheduled to attend; those received after the first 20 were returned home with a letter of explanation.

A reminder was sent home to the parents of children scheduled to participate one week before the program began. An announcement was made in school reminding the children when the program was to begin; an IRB approved flyer (Appendix C) was also placed in the foyer of the school as a reminder to the children. Assent was also obtained 
using an approved IRB form for the children at the first session of the program (Appendix D)

\section{Measurement}

A questionnaire entitled Your Physical Activity and Nutrition Check-Up was used to measure participants' level of physical activity and healthy lifestyle. The original version of this questionnaire was developed by Kids First RI (2008) as part of a wellness education workshop entitled Your Physical Activity Check-Up. The original questionnaire included 10 questions; the questionnaire was modified to include questions relating to nutrition as well as exercise, and the items were also reworded to be age appropriate for the targeted sample. The modified questionnaire includes nine questions and the title was changed to: "Your Physical Activity and Nutrition Check-Up" (Appendix E).

Weight was another outcome variable. Weight measurements were taken at the beginning and end of the program. The weights were recorded using a reliable and valid scale, and the same scale was used pre and post. The children were taken one at a time into the nurse's office where they were asked to take off their shoes and step on the scale. The weight was recorded on the weight record (Appendix F) in the same manner for all children, and confidentiality was maintained. Weight data was collected individually so privacy was protected.

The researcher developed a three-question evaluation tool with Likert type scale, which was distributed to the children at the end of the program (Appendix G). 


\section{Procedures and Program Implementation}

The program was a six week program running on Tuesdays and Thursdays after school beginning at 2:40 pm and running for 45 minutes until 3:25 pm. The program targeted the $4^{\text {th }}, 5^{\text {th }}$, and $6^{\text {th }}$ graders at George J. Peters Elementary School in Cranston and was held in the gymnasium/outdoor black top and the library. Accommodations were made for any children in the special needs population that were selected. Children were expected to attend all 12 sessions. If a child missed more than three sessions, they were allowed to continue in the program but their results were not included in the final results. The program was held immediately following the conclusion of school; therefore all participants were already at school and in the building so transportation to the program was not a problem. Arrangements were made for the children to be picked up after the session had ended at 3:25 pm. The parents were aware of the need to pick up their child, which was clearly stated in the Informed Consent Document the parents signed.

\section{Overview of individual sessions.}

The first session was a data collection session; all children who participated were informed of what the program was about and what was expected of them. The assent form was reviewed (Appendix D), and children had the opportunity at that time to sign their own assent to participate or choose to decline. They were assured that participation was voluntary and that they were free to withdraw at any time, though they were encouraged to complete the sessions. Next they were asked to complete a pre-test (see measurement section) to measure their knowledge on healthy food choices and how active they are. The questionnaire consisted of nine questions; the children either place a 
check in the column or circled their answer in a particular column. Each column was totaled and they received a score. Based on the score received the children were categorized as physically active and leading a healthful lifestyle, need to boost activity and choose healthier foods, or need ways to include activity and healthful food choices in their lifestyle. Finally, all children were weighed, individually and privately, in the nurse's office located next to the gym. The scale used was a reliable and valid scale; results were recorded and placed in a locked cabinet along with the results of the pre-test.

The second session focused on what the children thought about snack versus treat. Discussion time was provided, explaining the benefits and risks of both choices. Examples were provided of both a snack and a treat with sampling. A hand-out was given (Appendix $\mathrm{H}$ ) reviewing the information, with the intent being that children will bring it home to show their parents.

The third class explored what exercise meant to them. Discussion took place on how long they should exercise each day and what kind of exercise they should do. Preparation before exercise was discussed; the importance of proper hydration and stretching before any type of physical activity was stressed and demonstrated. Demonstration of all exercises was followed with active participation.

The remainder of the sessions (4-11) combined a 15 minute nutrition lesson with a 15 minute exercise lesson, followed by a 10 minute cool down and taste session. The taste session introduced new foods to the children that they may or may not have tasted before. The goal was to increase their exposure to and knowledge of good tasting, healthful snacks. The exercise sessions were intended to build on their current exercise patterns 
and invite new and creative ways to be active. The lessons proposed were based on reviewed articles on school-based interventions and the outcome measures.

The $12^{\text {th }}$ session was a summary of the previous sessions followed by a post test and weigh in. The post test was the same test given prior to beginning the program. Again, students were weighed individually and privately. At the conclusion of the program, further information was provided to the children and their families on healthy snack choices containing 100 calories or fewer and ideas for group exercise. The information provided was obtained from web sites such as: The New England Dairy and Food Council; My Pyramid.gov; and the CDC. Materials were copied and sent home with the children and the web sites were also supplied. This was done in an attempt to encourage continued behavior change through access to resources to guide their choices.

\section{Data Analysis}

Unique identifiers were used on the pre and post data and on the weight recordings and were destroyed as soon as the pre and post data had been matched. When data collection was completed, forms were placed in a locked closet in the nurse's office, only available to the investigator. Consent forms were filed separately from the data forms.

Descriptive statistics were performed on all study variables and differences between pre and post scores were examined. 


\section{Results}

Table 2 Pre-Test, Post-Test Knowledge Scores and Pre and Post Intervention Weights for All Participants $(N=17)$

\begin{tabular}{|c|c|c|c|c|c|c|}
\hline $\begin{array}{c}\text { Participant } \\
\text { number }\end{array}$ & $\begin{array}{c}\text { Pre-test } \\
\text { score }\end{array}$ & $\begin{array}{l}\text { Post-test } \\
\text { score }\end{array}$ & $\begin{array}{l}\text { Score } \\
\text { change }\end{array}$ & Pre-Weight & Post-Weight & $\begin{array}{l}\text { Weight } \\
\text { change }\end{array}$ \\
\hline 1 & 17 & 17 & 0 & $51 \mathrm{lbs}$. & $52 \frac{1}{2} \mathrm{lbs}$ & $+11 / 2 \mathrm{lbs}$. \\
\hline 2 & 21 & 24 & +3 & $93 \mathrm{lbs}$. & $94 \mathrm{lbs}$. & $+1 \mathrm{lb}$ \\
\hline 3 & 22 & 25 & +3 & $671 / 2 \mathrm{lbs}$ & $68 \mathrm{lbs}$. & $+1 / 2 \mathrm{lb}$ \\
\hline 4 & 20 & 23 & +3 & $59 \mathrm{lbs}$. & $60 \mathrm{lbs}$. & $+1 \mathrm{lb}$. \\
\hline 6 & 22 & 23 & +2 & 102 lbs. & $101 \mathrm{lbs}$. & $-1 \mathrm{lb}$. \\
\hline 8 & 20 & 25 & +5 & $108 \mathrm{l} / 2 \mathrm{lbs}$ & $114 \mathrm{lbs}$. & $+5 \frac{1}{2} \mathrm{lbs}$. \\
\hline 9 & 19 & 21 & +2 & $112 \mathrm{1} / 2 \mathrm{lbs}$ & $113 \mathrm{lbs}$. & $+1 / 2 \mathrm{lb}$ \\
\hline 10 & 23 & 23 & 0 & 79 lbs. & 77 1/2 lbs. & $-11 / 2 \mathrm{lbs}$ \\
\hline 11 & 20 & 22 & +2 & $115 \mathrm{l} / 2 \mathrm{lbs}$. & $1161 / 2 \mathrm{lbs}$. & $+1 \mathrm{lb}$. \\
\hline 12 & 24 & 23 & -1 & $63 \mathrm{lbs}$. & 63 lbs. & 0 \\
\hline 13 & 24 & 24 & 0 & 61 1/2 lbs. & 61 1/2 lbs. & 0 \\
\hline 14 & 26 & 24 & -2 & $59 \mathrm{lbs}$. & $60 \mathrm{lbs}$. & $+1 \mathrm{lb}$. \\
\hline 15 & 22 & 27 & +5 & $107 \mathrm{1} / 2 \mathrm{lbs}$. & $105 \mathrm{lbs}$. & $-2 \frac{1}{1} / 2 \mathrm{lbs}$ \\
\hline 16 & 19 & 25 & +6 & $123 \mathrm{1} / 2 \mathrm{lbs}$ & $125 \mathrm{lbs}$. & $+11 / 2 \mathrm{lbs}$. \\
\hline 18 & 24 & 24 & 0 & $90 \mathrm{lbs}$. & $91 \mathrm{lbs}$. & $+1 \mathrm{lb}$. \\
\hline 19 & 23 & 23 & 0 & $70 \mathrm{lbs}$. & 73 lbs. & $+3 \mathrm{lbs}$ \\
\hline 20 & 21 & 21 & 0 & 73 lbs. & 74 lbs. & $+1 \mathrm{lb}$. \\
\hline
\end{tabular}


Of the 128 potential participants, 49 returned a completed consent form; participation was on a first return basis. Therefore, the first 20 completed consent forms were randomly selected from the nurse's desk. The program included 20 participants, of which 17 completed the program. Data from the three participants who did not complete the program were excluded.

The participants consisted of seven boys (five 4th graders and two 6th graders) and 10 girls: (six 4th graders, three 5 th graders, and one 6 th grader). Table 2 illustrates a summary of the pre-post test knowledge data and the pre and post weights.

Table 3 illustrates the participants by direction of change: none, positive, or negative change. As can be seen, more than half of participants $(n=9 ; 52.9 \%)$ demonstrated an increase in knowledge in the post-test.

Table 3 Number of Participants $(N=17)$ by Direction of Change (None, Positive, Negative)

\begin{tabular}{|c|c|c|}
\hline \# of Participants & Score change range & Score change \\
\hline 6 & 0 & Unchanged score \\
\hline 9 & +2 to +6 & Increased score \\
\hline 2 & -1 to -2 & Decreased score \\
\hline
\end{tabular}

Table 4 illustrates the change in weights (positive; negative; no change) by participants. The majority of participants $(\mathrm{n}=12 ; 70.5 \%)$ increased weight from the beginning of the program to the end. 
Table 4 Participants' Change in Weight Post Program $(N=17)$

\begin{tabular}{|c|c|c|}
\hline \# of Participants & Weight change range & Weight change \\
\hline 12 & $+1 / 2 \mathrm{lb}$. to $+5^{1 / 2} \mathrm{lbs}$. & Increased weight \\
\hline 3 & $-1 \mathrm{lb}$. to $-2 \frac{1 / 2}{\mathrm{lbs}}$. & Decreased weight \\
\hline 2 & 0 & Unchanged weight \\
\hline
\end{tabular}

\section{Program Evaluation}

Table 5 illustrates the results of the three question program evaluation tool. All participants $(\mathrm{N}=17(100 \%)$ stated that they liked the program, the food tasting, and the program overall.

Table 5 Program evaluation results

\begin{tabular}{|c|c|c|c|}
\hline \# of Participants & Liked the program & $\begin{array}{c}\text { Liked the food } \\
\text { tasting }\end{array}$ & $\begin{array}{c}\text { Overall found } \\
\text { program to be fun } \\
\text { and enjoyable }\end{array}$ \\
\hline 17 & $100 \%$ & $100 \%$ & $100 \%$ \\
\hline
\end{tabular}




\section{Summary and Conclusions}

Over the past decade, childhood and adolescent overweight and obesity have been recognized in the United States (US) as a rapidly increasing, major pediatric health concern (Lee et al., 2009). Nearly one third of children nationwide are overweight (32\%) or obese (16\%), (Singh \& Katz, 2010), and approximately nine million children over six years of age are considered obese (Klish, 2010). From the literature, it is evident that school-based obesity prevention programs can and do have a positive impact on knowledge, attitudes, and behavior in children and adolescents.

The purpose of the project was to develop a school-based program focused on nutrition and exercise and aimed at encouraging and teaching healthful lifestyle choices and facilitating behavior change. The target population included $4^{\text {th }}, 5^{\text {th }}$, and $6^{\text {th }}$ grades at an elementary school in RI. Outcome variables measured were knowledge of healthy diet and exercise and body weight. Urie Bronfenbrenner's Ecological Theory (1979) and Nola Pender's Health Promotion Model (HPM) (2006) guided the development of the intervention, a nutrition and physical activity school based program. Bronfenbrenner's Ecological Theory emphasizes a child's biology as a primary environment that fuels development. The interaction between immediate family, community, environment, and societal surroundings guides development and has an influence on well-being.

The HPM places emphasis on the role of the person as a mediator in shaping health practices to optimize individual well-being. Health promotion focuses on the modification of health related behavior. After completing a needs assessment, the program content was developed based on the literature and clinical experience of the 
developer. A researcher developed pre-test was administered and body weight was measured before the start of the six-week educational program, which met twice a week. Each session included a nutrition lesson and an exercise activity, which was followed by a cool down, and tasting session. Upon program completion, a post test was administered, body weight was measured, and participants completed a brief evaluation of the program.

Of the 17 children that completed the program, nine demonstrated an increase in healthy diet and exercise knowledge, six remained unchanged, and two showed a decrease. The six participants whose scores did not change appeared to be already leading a healthy life style, based on their pre-test scores, and hopefully will continue to do so. It is unclear why scores of two participants decreased, but misinterpretation of the question is one acknowledged possibility. Weights post program demonstrated little change, though this was expected because the children were in a growth phase.

As supported in the literature, it is clear that both nutrition and physical education in schools can favorably impact knowledge scores. Further research is needed to study how to sustain those scores and to examine if that change in knowledge leads to actual behavior change, and if so, how that can be maintained. The most notable limitation to this program was time and duration. The program was offered only once, and the 12 week time period is clearly of short duration. The literature suggests that programs of relatively short duration (four months) can demonstrate a decrease in obesity: programs lasting longer than 12 months were also positively associated with effectiveness. Determining the most effective time period is an important pursuit. Another limitation of 
this program was that parental involvement was lacking. The literature validated that parental involvement is an essential component to a school-based intervention program. Families have a direct impact on their children's development of lifelong habits, including physical activity and nutritious eating, and ideally need to be educated and empowered to participate in the interventions. It must also be acknowledged that parental involvement adds complexity that was beyond the scope of this project. Due to the fact that this project was designed and implemented solely by this investigator, the sample was limited to 20 participants, though many more expressed interest. Future programs would benefit from increased number of participants to improve the impact and generalizability.

In conclusion, it is evident that childhood obesity is an epidemic (Lee et al., 2009), one that cannot be solved overnight. Obesity is a multi-factorial problem requiring interventions in the area of dietary habits, physical activity, healthy lifestyle education, and parental involvement. School-based exercise and nutrition programs have been shown to have a positive effect on obesity prevention, and using multiple, selected interventions are more effective than single interventions. Parental involvement seems to be a very beneficial intervention associated with obesity prevention. Kitzmann et al. (2010) noted that parental involvement in life style interventions was more successful in terms of achieving weight loss than was non-parental involvement.

The interaction between immediate family, community, environment, and societal surroundings guides development and has an influence on well-being. Improving dietary and lifestyle patterns and reducing obesity require a sustained multi-dimensional effort, 
which addresses not only individual behavior but also the environment, and conditions in which people live and make choices. The findings of this program support that if children are given the proper resources and support, basic knowledge, and are provided with choices for behavior change, they will potentially use the knowledge to make healthier choices. School-based prevention programs are necessary for several reasons. Most notably that large numbers of children can be monitored because most children go to school, eat two of their meals at school, exercising takes place in schools, schools are potentially able to influence children's behaviors toward healthy living; and finally peer groups can be supportive and boost motivation. In order to create this environment in schools and beyond, sweeping policy change is needed, and will be discussed next. 


\section{Recommendations and Implications}

The public is well aware that obesity is a growing national problem. The news media remind us of this weekly if not daily, with stories related to obesity. National obesity prevention programs including the Let's Move Campaign headed by First Lady Michelle Obama and the We Can program sponsored in part by the National Heart, Lung, and Blood Institute were designed to give parents, caregivers, and entire communities a way to combat childhood and adolescent obesity.

Food marketing to children is a public health concern and has a direct and powerful impact on young people's food preferences and eating behaviors, and can negatively affect their diet and weight. Changes have been seen in these areas; guidelines by the Center for Science in the Public Interest were published in 2005 to encourage food companies to be responsible with their advertising. Ads targeting children began to disappear from television, but they showed up instead online and at the movies. The issue is that these are only guidelines and not federal law; legislation needs to be introduced and passed into law restricting advertising to children.

Actions by the state legislature and local school districts imply a commitment to the fight against childhood obesity. State initiatives such as Initiative for Healthy Weights 2010 and Early Care and Education Initiative of 2011 are examples of plans to improve nutrition and physical activity, giving our children the opportunity to establish healthy habits necessary to shape their physical, emotional, and social well being. A proposed increase in the soft drink tax, healthier food choices in the school lunch program, and an emphasis on preventative care by pediatricians are other state strategies for obesity 
prevention. Conferences have been organized by pediatricians in the state to educate fellow pediatricians on the importance of childhood obesity prevention and have worked on policy initiatives related to obesity. The commitment of the pediatricians to the fight against obesity, combined with a growing shortage of primary care physicians and an increase in health care demands, will increase the need for Nurse Practitioners (NPs), Advanced Practice Registered Nurses (APRNs), Certified School Nurse Teachers (CSNTs), and Advanced Practice Public Health Nurses (APPHNs). Expansion of nurses in these roles will be needed to accommodate increases in patient visits and to provide individualized attention and expertise.

In 2008, the Rhode Island General Assembly passed a law that requires all schools to implement health education and physical education based on Rhode Island Education Frameworks; this law will take full effect in the 2012-2013 school year. Several strategies for obesity prevention in schools have been implemented. One example is that only healthy snacks and beverages can be made available for sale in vending machines, a la carte, and at fundraisers on school premises.

The local YMCAs have taken the initiative to develop The Community Healthy Living Index (CHLI) to help communities transform themselves into ones that provide opportunities for individuals and families to be active, eat right, and live healthier. The school nurse plays an important role since he/she is the health professional providing care for the school community. A primary role of the school nurse is to support student learning, which can be accomplished by implementing strategies that promote student health and safety as well as that of the staff. The nurse has been a part of the school 
community since the late 1800 's. Over the years, the increase in chronic disease, mental health issues, and high-risk behaviors in students has necessitated that school nurses gain expertise in public health as well as pediatric and mental health. The increased need for school nurses also increased with the passage of Public Health Law 94-142 in 1975, which required the mainstreaming of physically and mentally challenged students into the general population. The complexity of the school community is ever changing and the need for more school nurses is evident. School nursing does require additional training; one consideration would be to link the APPHN program in the RIC School of Nursing (SON) with that of the School Nurse Teacher Certification. Such would enhance the ability to equally focus on education and health within the school nurse teacher role, especially important in the current climate where more families are without health care and are using the school nurses as a primary care office.

It is unrealistic to expect immediate change; knowing that the current public health obesity crisis has been decades in the making, it can be anticipated that it will take decades to produce notable change. The challenge of significantly impacting obesity trends will not be easy and will require that programs be established to meet individual community needs. Eventually, nationwide programs of healthy lifestyle education and physical fitness should be implemented in all schools. This obviously will require a national effort and national funding support. Programs should be implemented at the earliest level in the schools and continue through high school in order to increase the potential of producing the best possible outcomes. School authorities need to prioritize: schools are spending more time on reading and mathematics, yet it can be argued that 
physical activity and nutrition education are equally important and require that increased time be allotted for teaching in these areas. Programs of this type pose several challenges, including cost, support from stakeholders, and resistance from school administration. Extending the school day may be one option, which could facilitate more time in the day for nutrition education and exercise. Another option could be standardizing the requirements for school nurse teachers, and requiring a school nurse teacher in every school building throughout the districts and throughout the states. School nurse teachers can assist in the obesity fight by encouraging healthy snack choices through a monthly tip via newsletter, web page, or visual poster in the lunchroom. Visiting a different classroom on a daily basis during snack time and providing a five to seven minute lesson on the snack choices would encourage healthier choices. Continued reinforcement over time can motivate and encourage behavior change. District wide policies regarding celebrations such as birthdays, Christmas, and Halloween should be considered, and examining non-food items as celebratory choice such as pencils, erasers, and stickers as opposed to food items should be emphasized. Stakeholders should consider implementing school-based interventions as long term strategies for preventing and managing childhood overweight and obesity. It is up to all of us to help reverse the obesity epidemic that has been decades in the making. 


\section{References}

Addison, J. T. (1992). Urie Bronfenbrenner. Human Ecology, 20(2), 16-20.

America's Health Ranking. (2009).

http://www.americashealthranking.org/yearcompare/2009/2009/RI.aspx

Anderson, P. M., \& Butcher, K. F. (2006, Spring). Childhood obesity: Trends and potential causes. The Future of Children, 16(1). 19-45.

Bronfrenbrenner, U. (1979). Ecological theory. Retrieved from http://www.des.emory.edu/mfp/302/302bron.PDF

Center for Disease Control (2009, May). Center for disease control and prevention, National center for health statistics. Prevalence of overweight among children and adolescents ages 6-19 tears. Retrieved from http://www.cdc.gov/nchs/products/pubs/pubd/hestats/over99fig1.htm.

Center for Disease Control (2010, August 3,). Vital signs: State specific obesity prevalence among adults. Morbidity and Mortality Weekly Report, 59, 1-9. Retrieved from $\mathrm{http} / /$ www.cdc.gov $/ \mathrm{mmwr} / \mathrm{preview} / \mathrm{mmwrhtml} / \mathrm{mm} 59 \mathrm{e} 0803 \mathrm{al} . \mathrm{htm}$ ?s_cid_=mm5 9e0803al

Center for Disease Control (2011). http://www.cdc.gov/mmwr/pdf/wk/mm6036.pdf Childhood obesity in the united states: facts and figures. (2005, September). Institute of Medicine. Retrieved from http://www.iom.edu/ /media/files/Report\%20Files/2004/preventing-childhoodobesity-Health-in-the-balance 
Gauvain, M., \& Cole, M. (2005). Readings on the development of children (4th ed.). New York, NY: Worth Publishers.

Haskins, R., Paxson, C., \& Donahue, E. (2006, Spring). Fighting obesity in the public schools. The Future of Children, 16(1), 1-8.

Health problems of obese children. (2007, February). Childhood Obesity. Retrieved from http:/hcd2.bupa.co.uk/fact_sheets/html/child_obesity.html?print

HealthyPeople.gov. (2010).

http://www.healthypeople.gov/2020/topicsobjectives2020/overview.aspx?topicid $=31$

Kitzmann, K. M., Stanley, C. M., Dalton, W. T., II, \& Beech, B. M. (2010). Lifestyle interventions for youth who are overweight: A meta-analytic review. Health Psychology, 29, 91-101.

Klish, W. J. (2010). Definition; epidemiology; and etiology of obesity in children and adolescents. UptoDate, 1-26. Retrieved from http://www.uptodate.com/online/content/topic.do?topicKey=pedigast/15483\&vie $\mathrm{w}=$ print

Koebnick, C., \& Heller, S. (2010, March 18). More kids now extremely obese. Journal of Pediatrics. Retrieved from http://nlm.nih.gov/medlineplus/print/news/fullstory_96575.html

Lee, P., Lai, H., Chou, Y., Chang, L., \& Chang, W. (2009, September). Perceptions of exercise in obese school-aged children. Journal of Nursing Research, 17(3), 170- 
Lytle, L. A. (2009). Examining the etiology of childhood obesity: The idea study (10.1007/s10464-009-9269-1). : Division of Epidemiology and Community Health, University of Minnesota

Overweight and obesity. (2010). Retrieved from http://kidshealth.org/PageManager.jsp?dn=KidsHealth\&lic=107\&cat_id=189\&art icle_set $=30265$

Pender, N. J., Murdaugh, C. L., \& Parsons, M. A. (2006). Individual models to promote health behavior. In M. Connor (Ed.), Health promotion in nursing practice (pp. 35-73). Upper Saddler River, NJ: Prentice Hall.

Peterson, S. J., \& Bredow, T. S. (2009). Middle range theories Applications to nursing research (2nd ed.). Philadelphia, PA: Lippincott Williams \& Wilkins.

Polit, D. F., \& Beck, C. T. (2008). Developing a theoretical or conceptual context. In nursing research Generating and assessing evidence for nursing practice (pp. 139-165). New York, NY: Lippincott Williams \& Wilkins.

Sallis, J. F., McKenzie, T. L., Kolody, B., Lewis, M., Marshall, S., \& Rosengard, P. (1999). Effects of health-related physical education on academic achievement. Project SPARKS, Research Quarterly for Exercise and Sports, 2, 127-134.

Seo, D., \& Sa, J. (2010). A meta-analysis of obesity interventions among US minority children. Journal of Adolescent Health, 46, 310-323.

Singh, G. K., \& Katz, D. L. (2010, May 3). Obesity a bigger threat to kids in southern states. Pediatrics \& Adolescent Medicine. Retrieved from http://www.nlm.nih.gov/medlineplus/print/news/fullstory_98317.html 
Smith, M. N., \& Wolf, E. (2008). Exposure to media damages children's long term health. Retrieved from Yale University School of Medicine: http://www.commonsensemedia.oeg/sites/default

Stokols, D. (1996, March/April). Translating social ecological theory into guidelines for community health promotion. American Journal of Health Promotion, 10(4), 282298.

Story, M., Kaphingst, K. M., O’Brien, R. R., \& Glanz, K. (2007, November 21,). Creating healthy food and eating environments: Policy and environmental approaches. The Annual Review of Public Health, 29, 253-272. doi: 10.1146

Suarez, C. G., Worley, A., Somers, K. G., \& Dones, V. (2009, November). School-based interventions on childhood obesity A meta-analysis. American Journal of Preventive Medicine, 37, 418-427.

Vital signs: State-specific obesity prevalence among adults--United States. (2010, August). $M M W R, 1-9$. Retrieved from http://www.cdc.gov/mmwr/preview/mmwrhtm1/mm59e0803al.htm?s$\mathrm{cid}=\mathrm{mm} 59 \mathrm{e} 0803 \mathrm{al}-$

White House Task Force on Childhood Obesity Report to the President. (2010). Solving the problem of childhood obesity within a generation (). Washington, DC: U.S. Government Printing Office.

Zenzen, W., \& Kridli, S. (2008). Integrated review of school-based childhood obesity prevention programs. Journal of Pediatric Health Care, 23(4), 242-258. doi: 10.1016/j.pedhc.2008.04.0 
Appendix A

\section{GEORGE j. PETERS ELEMENTARY SCHOOL \\ 15 MAYBERRY STREET \\ CRANSTON, RHODE ISLAND 02920 \\ CRANSTON PUBLIC SCHOOLS}

\section{PATRICIA CAPORELLI PRINCIPAL}

To whom it may concern:

I am the Principal at George J. Peters Elementary School and I am writing this letter to inform you that Darlene Amalfitano has permission to implement her program on Nutrition and Exercise at George J. Peters Elementary School in Cranston. The six week program will meet two times per week and will target the $4^{\text {th }}, 5^{\text {th }}$, and $6^{\text {th }}$ grade students. The parents will be asked to provide permission forms for the children who wish to participate and will not be allowed to participate without proper consent. The program guidelines limit the number of students so it will not exceed 20 students. I look forward to this important and informative program implemented in our school. And I applaud Mrs. Amalfitano's efforts to help our students learn some lifelong lessons now and also hopefully assist them in maintaining healthy life styles for the future

If you have any questions please feel free to contact me at school 270-8199.

Thank you, Patricia Caporelli, Principal 


\section{CONSENT DOCUMENT \\ Rhode Island College \\ Appendix B}

Nutrition and Exercise Program

To the parent or legal guardian of

My name is Darlene Amalfitano RN, and I am a graduate student at Rhode Island College. I would like to ask permission for your child to participate in a program on nutrition and exercise. Your child was selected for this program because she/he is a 4th, 5th, or 6th grade student at George J. Peters Elementary School. Your child will also be asked whether he/she wants to participate and his/her wishes will be followed.

\section{Description of the project:}

This program is a school based nutrition and exercise program aimed at encouraging and teaching healthful life style choices and to facilitate behavioral change.

\section{What will be done:}

If you allow your child to participate in this program here is what will happen:

- You will be asked to sign this consent form allowing your child to participate in the program.

- At the first meeting the program will be explained to your child and she/he will be asked to sign a assent form stating that they understand the program and would like to participate.

- At the first meeting they will also be asked to complete a questionnaire about their eating and exercise habits and be weighed in a private area, one at a time. All information obtained will be kept confidential.

- The second meeting will focus on what the children think a snack is verse a treat. Discussion time will be provided, sampling of a treat and a snack will be provided and a handout will be provided.

- The third meeting will go over what exercise means to them, how long each day they should exercise and what kind of exercise they should do. Preparation before exercise will be discussed; demonstration of all exercises will follow with active participation.

- The remainder of the meetings (4-11) will be a combination of a 15 minute nutrition lesson followed by a 15 minute exercise session ending with a 10 minute cool down and taste session. The taste session will introduce new foods to the children that they may or may not have tasted before. The goal is to increase their knowledge of good tasting-healthful snacks.

- The $12^{\text {th }}$ meeting will be a summary of the previous meetings followed by a questionnaire they will be asked to complete. The questionnaire will be the same one given prior to beginning the program; their weight will also be taken and recorded.

- The results of the questionnaire and the weight measurements will be shared with the child and their parent.

- The program is limited to 20 children-the first 20 permission slips returned to me will be the children selected.

- The program will be held immediately following the conclusion of school.

- The program will run for six weeks, with meeting two times per week on Tuesday and Thursday's beginning at 2:40 pm and ending at 3:25.

- You will need to pick up your child when the program ends at 3:25.

\section{Risks or discomfort:}

The risks associated with this program are minimal, meaning that they are about the same as what someone would experience in their typical daily activities. The most likely risk is that your child may become bored during the program and may want to quite. The hope is that your child completes all 12 sessions of the program. 


\section{Benefits of this study:}

The benefits of your child taking part in this program are increased knowledge of healthful diet and exercise choices and reducing or maintain weight.

\section{Confidentiality:}

Your child's part in this program is confidential. None of the information obtained will identify her/him by name. The questionnaire and weight record will have a unique identifier on it that only your child and I will know. All papers will be stored in a secure location for the duration of the program. At the conclusion of the program any information obtained will be destroyed.

Initial here to indicate that you have read and understand the above information

\section{Decision to quit at any time:}

The decision to take part in this program is up to you and your child and is completely voluntary. Your child will be asked whether she/he wants to participate. Both you and your child may decline to participate or may change your mind at any time with no negative consequences. If you start to participate and change your mind your child may leave at any time without question.

\section{Contacts and Questions}

If you have any questions about the program, you may contact Darlene L. Amalfitano RN, SNT at 2708199.

If the researcher cannot be reached, or if you would like to talk to someone other than the researcher about (1) your rights as a participant, (2) research-related injuries or problems, or (3) other issues/concerns you have about your participation in this program, please contact the Chair of the Institutional Review Board at IRB@ric.edu, or by phone (401-456-8228), or by writing, Chair, IRB; c/o Office of Research and Grants Administration; Roberts Hall; Rhode Island College; 600 Mount Pleasant Avenue; Providence, or Cynthia Padula , Professor of Nursing at cpadula@ric.edu or by phone at 456-9720.

You will be given a copy of this permission form to keep.

\section{Permission Statement:}

I have read this Permission Form. My signature below means that I understand the information and agree to give permission for my child to participate in this program. I am over 18 years of age, and either the parent or legal guardian of the child.

Child's name:

Please initial each section separately as you have the right to agree to each part of the proposal on an individual basis.

I __ Do _ Do Not give permission for my child to participate in this program

Parent initials

I D_ Do_ Do Not give permission for my child to be weighed 
I __ Do _ Do Not give permission for my child to take the questionnaire

Parent initials

I _ Do_ Do Not give permission for my child to sample food

Parent initials

\begin{tabular}{|l|l|l|}
\hline & & \\
\hline Signature of parent/guardian & & Signature of researcher \\
\hline & & \\
\hline Print name of parent/guardian & & Print name of researcher \\
\hline & & \\
\hline Date & & \\
\hline
\end{tabular}




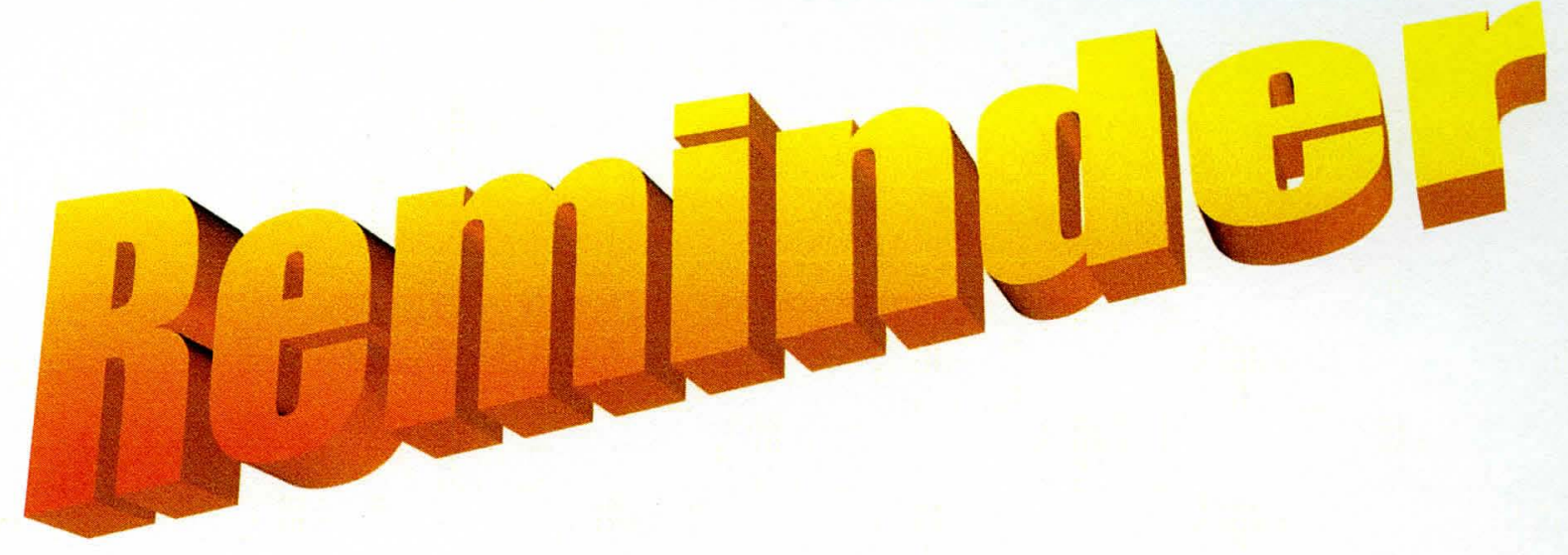

Appendix C

\section{The Nutrition and \\ Exercise Program}
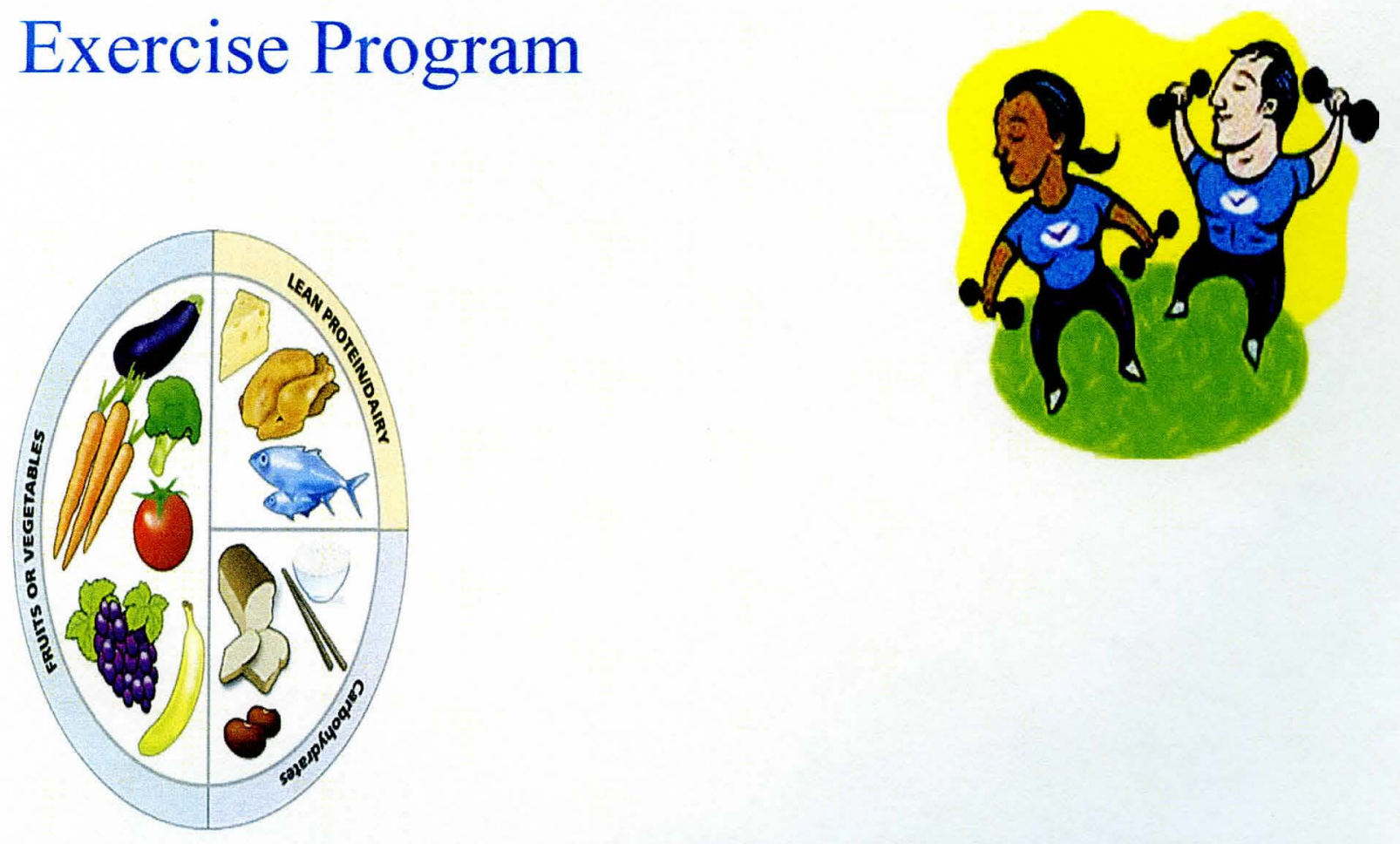

\section{Begins Next Week}




\begin{abstract}
Assent Document
Appendix D

My name is Mrs. Amalfitano, and I have developed a program aimed at encouraging and teaching healthful life style choices.

If you choose to take part in this program, then you will be asked to complete a survey about your eating and exercise habits, and you will be weighed. You will be asked to stay two days after school for about an hour for 6 weeks. During each meeting you will learn about healthful food choices, exercise with active involvement and sample foods you may or may not have tasted before.

I have already told your parents about the program, and they said it is okay for you to do it if you want to. If you don't want to be in the program, you can say "No" and nobody will be upset at you and nothing bad will happen. Also you can change your mind at any time and nobody will be upset and nothing bad will happen.
\end{abstract}

You need to know that your name and what you tell me or what you do will be told to your parents only.

So, like I said earlier, you don't have to do this if you don't want to and nobody will be upset.

Do you have any questions about this program?

Would you like to do it?

I have read this assent form. My signature below means that I understand the information and agree to participate in this program.

Signature of participant Signature of researcher

Print name of participant

Print name of researcher 


\section{Appendix E \\ Your Physical Activity and Nutrition Check-up}

Place a $\sqrt{ }$ in the proper box for questions 1-5, circle $ว$ your answer in the proper box for questions 6-9 and

Unique Identifier: see how you measure up.

\begin{tabular}{|c|c|c|c|}
\hline Activity & Frequently & Sometimes & Never \\
\hline \multicolumn{4}{|l|}{$\begin{array}{l}\text { 1. Do you exercise } \\
\text { daily? }\end{array}$} \\
\hline \multicolumn{4}{|l|}{$\begin{array}{l}\text { 2. I enjoy spare time } \\
\text { sports (i.e. tennis, } \\
\text { volleyball, basketball). }\end{array}$} \\
\hline \multicolumn{4}{|l|}{$\begin{array}{l}\text { 3. I limit TV watching } \\
\text { to one or two hours a } \\
\text { day. }\end{array}$} \\
\hline \multicolumn{4}{|l|}{$\begin{array}{l}\text { 4. I stretch and } \\
\text { strengthen my muscles. }\end{array}$} \\
\hline \multicolumn{4}{|l|}{$\begin{array}{l}\text { 5. I take part in aerobic } \\
\text { activity (i.e. Biking, } \\
\text { running, swimming). }\end{array}$} \\
\hline $\begin{array}{l}\text { 6. What time of night do } \\
\text { you eat dinner? }\end{array}$ & $5 \mathrm{pm}$ & $6 \mathrm{pm}$ & $7 \mathrm{pm}$ \\
\hline $\begin{array}{l}\text { 7. What type of food do } \\
\text { you consider a snack? }\end{array}$ & Fruit & Chips & Cookies \\
\hline $\begin{array}{l}\text { 8. What type of food do } \\
\text { you consider a treat? }\end{array}$ & Candy Bar & Celery & Ice Cream \\
\hline $\begin{array}{l}\text { 9. What would be your } \\
\text { first choice for a healthy } \\
\text { dinner? }\end{array}$ & $\begin{array}{c}\text { Grilled chicken, } \\
\text { potato and } \\
\text { vegetable }\end{array}$ & $\begin{array}{c}\text { Macaroni and } \\
\text { cheese }\end{array}$ & $\begin{array}{c}\text { Chicken nuggets } \\
\text { and French } \\
\text { Fries }\end{array}$ \\
\hline \multicolumn{4}{|l|}{ My total ل's and O's } \\
\hline Multiple by & $\mathrm{X} 3$ & $\mathrm{X} 2$ & $\mathrm{X} 1$ \\
\hline My subtotal is & & & \\
\hline
\end{tabular}

By adding my subtotals together,

Check-up scale:

My total check-Up score is:

My score $=21-27$ : I lead a physically active and healthful lifestyle! I plan to continue it.

My score $=15-20$ : I need to boost activity and choices of healthful food. I will try this check-up again in 6 weeks.

My score =9-14: I need to find more ways to include activity and healthful food choices in my lifestyle! 
Appendix F

Weight Record

Unique Identifier:

\begin{tabular}{|c|c|c|}
\hline Session & Date & Weight \\
\hline 1 & & \\
\hline 12 & & \\
\hline
\end{tabular}




\section{Appendix G \\ Program Evaluation}

Please circle the number on how you felt about the Exercise and Nutrition Program. One you liked the program a lot and five you did not like the program at all.

1. I enjoyed the program and learned some ways to be healthier.

$\begin{array}{lllllll}\text { Agree } & 1 & 2 & 3 & 4 & 5 & \text { Disagree }\end{array}$

2. I enjoyed the food tasting portion of the program.

$\begin{array}{lllllll}\text { Agree } & 1 & 2 & 3 & 4 & 5 & \text { Disagree }\end{array}$

3. Overall the program was fun and enjoyable.

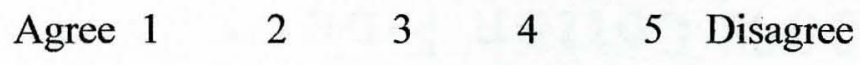


Healthier eating improves your over all health and well being

Healthier eating along with exercise improves over all life!

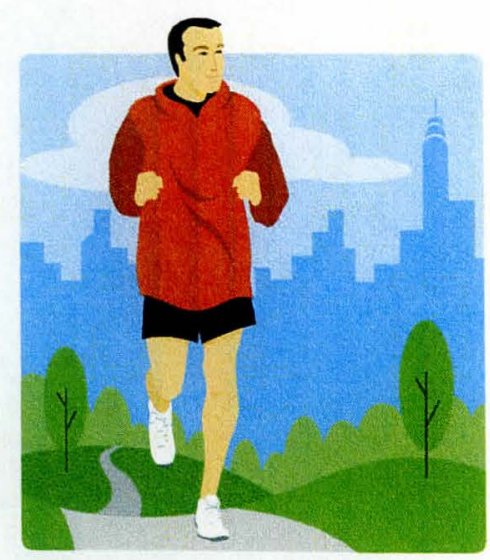

Did you know?

Walking 1 mile burns about 100 calories. Adding a 1 mile walk daily results in a 10-pound per year weight loss.
Appendix $\mathrm{H}$

D.Amalfitano RN, BSN, CSNT

R.I. Department of Health

http://www.healthri.ri.gov/disease/lhm/ publications.php

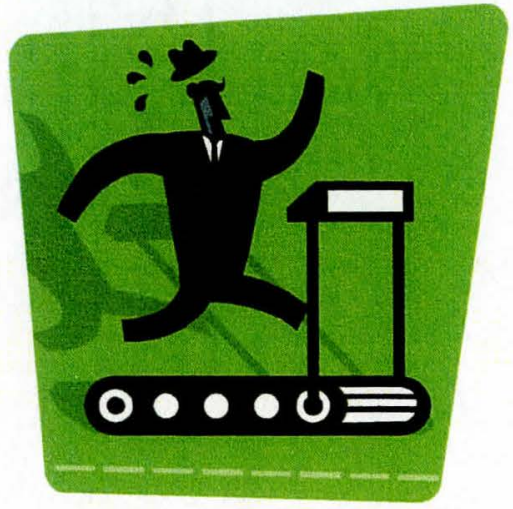

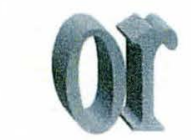
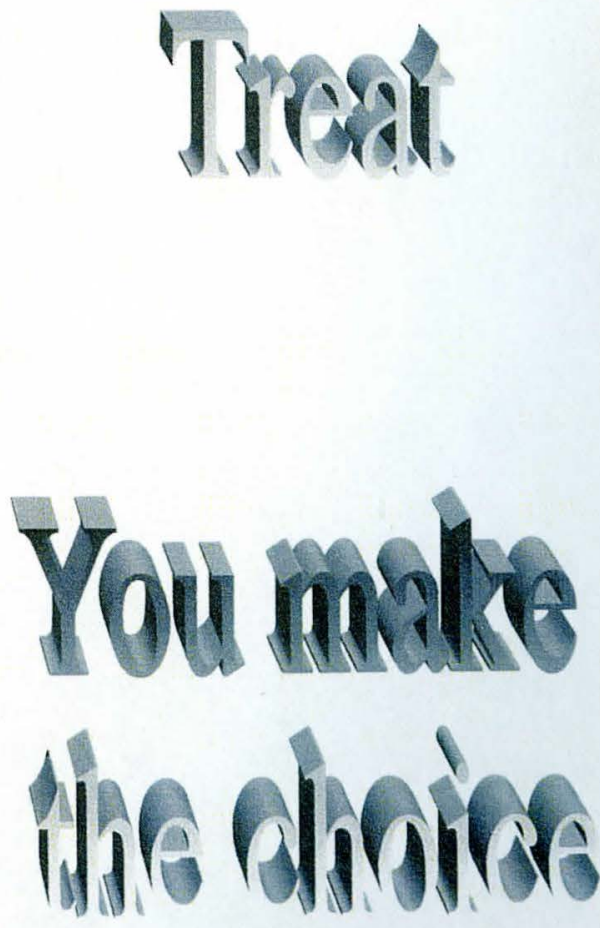


\section{What is a Snack?}

A snack is an everyday inbetween meal item that fills the hunger spot to get you through to the next meal; a healthy well balanced food item.

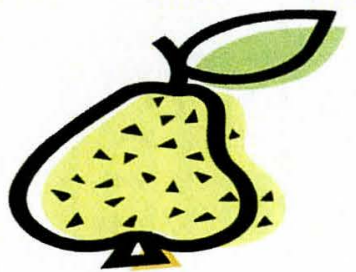

\section{What is a Treat?}

A treat is a food that is high in fat, calories, sugars and sodium (salt). A special occasion food that is not eaten often.

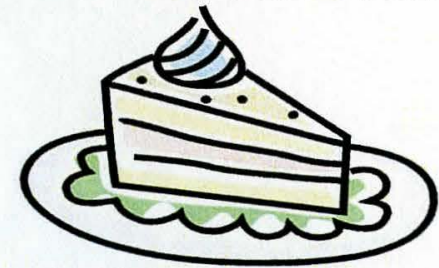

\section{Make the right choice!}

$\underline{\text { WHY? }}$

1. Snacks are healthier

2. Less calories

3. Keeps your energy level high

4. Keeps your mind alert

1. Treats are not as healthy

2. Have more calories

3. Make you feel good right away, then when the sugar burst is gone you 're even more tired.

\section{Examples:}

Snacks:

Carrot and celery sticks

Fruit

Yogurt

Low fat fruit bars

Raisins

Whole-wheat crackers with cheese

Rice cakes

Whole-wheat fig bars

Fruit smoothies

Pretzels

Treats:

Chocolates Brownies

Candy bars Doritos

Pop tarts Cheetos

Twinkies Potato

Cupcakes Chips

Donuts

Cake 